\title{
SELEÇÃO DO CONHECIMENTO COMO OPERAÇÃO ANTAGÔNICA
}

\author{
KNOWLODGE SELECTION AS ANTAGONISM OPERATION
}

\section{SELECIÓN DEL CONOCIMIENTO COMO OPERACIÓN ANTAGÓNICA}

\author{
Carmen Teresa Gabriel Le Ravallec ${ }^{1}$ \\ Ana Angelita da Rocha ${ }^{2}$
}

\section{RESUMO}

O presente artigo busca rever a trajetória de Michael F. D. Young (1971; 2000; 2008; 2010; 2011, 2014, 2014 a, 2016) para discutir a significação da seleção do conhecimento escolar. Tal proposta tensiona o debate do conhecimento escolar à luz da teoria política, a partir da discussão de antagonismo empreendida por Ernesto Laclau e seus interlocutores (2000; 2005). Com essa tessitura teórica, o artigo defende a relação entre o conhecimento escolar e uma abordagem da teoria política que valoriza a função epistemológica da escola, em tempos de reformas curriculares em escala nacional.

PALAVRAS-CHAVE: Teoria Curricular. Antagonismo. Conhecimento Escolar.

\section{ABSTRACT}

This article aims to review the career considerations of Michael F. D. Young $(1971 ; 2000 ; 2008 ; 2010 ; 2011$, 2014, 2014 a, 2016) to discuss the significance the school knowledge selection. This aim stresses the discussion of school knowledge in the light of political theory, from the discussion of antagonism undertaken by Ernesto Laclau and his interlocutors $(2000,2005)$. With this theoretical composition, the paper defends the relationship between curricular school knowledge and a political approach to value the epistemological function of the school, in times of curriculum reform on a national scale.

KEYWORDS: Curriculum Theory. Antagonism. School Knowledge.

\section{RESUMEN}

Este trabajo tiene como objetivo revisar la historia de Michael F . D . Young (1971; 2000; 2008; 2010; 2011, 2014, 2014 a, 2016) para discutir la importancia de la selección del conocimiento escolar. Esta propuesta tensiona la discusión del conocimiento escolar bajo la lente de la teoría política, desde el antagonismo de la discusión llevada a cabo por Ernesto Laclau y sus colaboradores (2000; 2005). Con esta herramienta teórica, el trabajo defiende la relación entre el conocimiento escolar y un acercamiento a la teoría política para valorar la función epistemológica de la escuela en tiempos de reforma curricular en escala nacional.

PALABRAS CLAVE: Teoría Curricular. Antagonismo. Conocimiento Escolar.

\footnotetext{
${ }^{1}$ Doutora em Educação - Pontifícia Universidade Católica do Rio de Janeiro (PUC-RJ) - Rio de Janeiro, RJ - Brasil. Professora e diretora - Universidade Federal do Rio de Janeiro (UFRJ) - Rio de Janeiro, RJ - Brasil. E-mail: carmenteresagabriel@gmail.com

${ }^{2}$ Doutora em Educação - Universidade Federal do Rio de Janeiro (UFRJ) - Rio de Janeiro, RJ - Brasil. Professora adjunta Departamento de Didática da Faculdade de Educação - Universidade Federal do Rio de Janeiro (UFRJ) - Rio de Janeiro, RJ Brasil. E-mail: geo.ana.angelita@gmail.com

Submetido em: 02/05/2016 - Aceito em: 10/10/2016

(C) ETD-Educação Temática Digital Campinas, SP $\quad$ v.19 $\quad$ n.3 $\quad$ p. 844-863 jul./set. 2017




\section{INTRODUÇÃO}

Este artigo é motivado pelos debates em torno da demanda por um currículo nacional, formulada no âmbito de setores privados e públicos da sociedade brasileira contemporânea, como, por exemplo, o Movimento pela Base Nacional Comum ${ }^{i}$ e as proposições curriculares previstas no vigente Plano Nacional de Educação, sancionado como lei 13.005/2014. Ao mobilizarem sentidos de currículo nacional, em meio às lutas políticas que envolvem a hegemonização de um projeto particular de escola e de sociedade democrática, esses debates instigam-nos a resgatar a problemática da seleção do conhecimento escolar como recorte privilegiado para a reflexão política do campo educacional. Em outras palavras, a seleção é percebida aqui como categoria de forte potencial heurístico nas análises políticas sobre as atuais tendências curriculares no Brasil.

Como pensar a questão da seleção curricular em meio aos debates acerca da produção de um currículo de "base comum" em "escala nacional"? Cientes das inquietações provocadas por essa interrogação, especialmente no atual cenário de proposições curriculares no Brasil, nosso texto aposta na releitura das contribuições teóricas de Michael F.D. Young para o debate sobre a seleção do conhecimento. A escolha desse autor não foi aleatória. Além de sua produção intelectual atravessar décadas e continuar sendo incorporada por diferentes pesquisadores brasileiros do campo educacional, a interlocução estabelecida pelos defensores da construção de uma base nacional comum com algumas de suas mais recentes proposições reforça, ainda mais, a pertinência dessa escolha. ii

Importa sublinhar que não se trata aqui, contudo, de especular sobre a influência de Michael Young no Movimento pela Base Nacional Comum tampouco analisar como esse movimento incorpora e interpreta as contribuições deste autor. Sabemos que são múltiplas e heterogêneas as leituras passíveis de serem feitas das obras dos autores escolhidos como interlocutores. A título de exemplo, e diretamente relacionado ao diálogo referido, cabe sinalizar que no artigo traduzido como "Teoria de currículo: o que é e por que é importante", Michael Young (2014) definiu uma concepção alternativa da função normativa de currículo que diverge frontalmente daquele postulado pelo Movimento pela base nacional: "Na minha visão, se o currículo for definido por resultados, competências ou, de forma mais abrangente, avaliações ele será incapaz de prover o acesso ao conhecimento" (2014:195).

O exemplo acima, apenas um entre tantos outros, reafirma a pluralidade de interpretações que circulam no campo educacional e indica a heterogeneidade dos

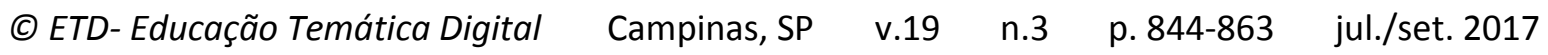


leitores de Young. Assim, nos interessa menos explorar essas múltiplas interpretações do que reconhecer que seus escritos vêm impactando direta e indiretamente as últimas gerações de teorias e políticas curriculares. Com efeito, nos parece oportuno inventariar alguns registros de Young reconhecendo nele tanto as potencialidades quanto os limites para discutir as intencionalidades universais nas políticas curriculares.

Consideramos pois, a revisão de suas discussões sobre a seleção do conhecimento escolar como tática para inventariar algunss que emergem no debate contemporâneo da reforma curricular. Referimo-nos mais particularmente à significação mais recente de seleção do conhecimento escolar em Young $(2008,2014,2016)$ que recupera a ideia de objetividade do conhecimento, como elemento chave na reflexão da política curricular.

Inspirado pelas contribuições da abordagem discursiva de Ernesto Laclau e Chantal Mouffe (2005) para a teorização política contemporânea, o objetivo principal deste ensaio é discutir os sentidos de seleção curricular, atribuídos por Young. Esse exercício reconhece especialmente que seus últimos escritos trazem uma autocrítica sobre algumas de suas formulações na década de 70 , quando afirmava e problematizava a centralidade da base sociológica na seleção do conhecimento.

Apoiadas assim, nas lentes da teoria política, particularmente no conceito de antagonismo (LACLAU, 2009), nossa proposta é problematizar o sentido de objetividade mobilizado nas produções recentes de Young (2008, 2011, 2014, 2014 a, 2016) ao interpretar a seleção do conhecimento em propostas curriculares. $O$ argumento central consiste em simultaneamente reconhecer a importância e a pertinência da discussão no campo curricular sobre a objetivação do conhecimento escolar e combater perspectivas essencialistas e deterministas na leitura do social. Para tanto, defenderemos neste ensaio a concepção da seleção do conhecimento como operação antagônica.

Na primeira seção do artigo, intitulada como Uma leitura da categoria "seleção" na obra de Michael Young, repercutiremos especialmente a crítica que o autor realiza de suas reflexões produzida nos anos de 1970. Neste exercício, sublinharemos os deslocamentos em suas interpretações acerca da categoria seleção curricular ao longo dessas últimas quatro décadas. Entendemos que Michael Young, em seus estudos recentes $(2007,2008,2014,2016)$ oferecem elementos importantes para repensar a questão da seleção, ao reorientarem o foco de suas reflexões curriculares da estratificação do conhecimento que sustenta a afirmação do currículo como um "arbitrário cultural" - tal como defendido por Bourdieu (1971) - para a diferenciação do conhecimento discutida nas teses de Basil Bernstein, como argumento central da defesa da objetivação do conhecimento.

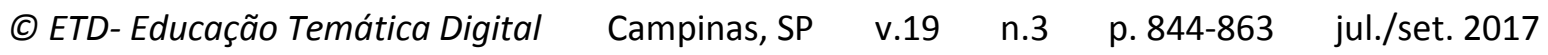
[846] 
Tal reorientação será problematizada na segunda seção, chamada de $A$ seleção como antagonismo: uma questão curricular, tendo como perspectiva de análise as contribuições oriundas do debate sobre antagonismo, no âmbito da teoria do discurso de Ernesto Laclau e de seus interlocutores. A opção por essa abordagem tem por objetivo valorizar a discussão da seleção como categoria de análise e da prática política no campo do currículo. Para tal dialogamos com e contra os estudos de Michael Young.

Se por um lado, os escritos mais recentes desse autor têm o mérito de enfrentar o desafio teórico relacionado à questão da objetivação do conhecimento escolar após as críticas formuladas no âmbito das teorizações curriculares críticas, a nossa leitura de Young aponta, por outro lado, que - nesse mesmo movimento em defesa da objetivação discursos essencialistas tendem a ser reatualizados, enfraquecendo tal defesa.

No decorrer deste ensaio, a partir de nossas convergências e divergências em relação ao autor em destaque, argumentaremos a favor da defesa da objetivação do conhecimento escolar a partir de outra postura epistêmica. Ao defendermos que a vitalidade da seleção do conhecimento escolar está no ato de percebê-la como uma operação antagônica em meio às lutas pela sua significação, reconhecemos simultaneamente a importância do enfrentamento assumido por Young e a potencialidade de operarmos com outros entendimentos de objetividade tal como proposto pela abordagem discursiva aqui privilegiada. Considerando as controvérsias e disputas em torno da agenda educacional contemporânea, este estudo se constrói, portanto, a partir da hipótese que vimos defendendo em nossas pesquisas de que a seleção do conhecimento escolar é uma operação curricular discursiva incontornável que se articula contingencialmente em meio à gestão de múltiplas demandas que interpelam as instituições de formação contemporâneas.

\section{UMA LEITURA DA CATEGORIA “SELEÇÃO” NA OBRA DE MICHAEL YOUNG}

Nesta seção, nosso objetivo é tratar - ainda que brevemente - da trajetória do pesquisador britânico do Michael F. D. Young para questionar as significações de "seleção", o que para nós, em função do quadro teórico no qual trabalhamos, implica necessariamente na interpretação dos projetos em disputa para definir o conhecimento escolar.

Como já mencionado anteriormente, escolhemos esse autor em função de seus proeminentes trabalhos que influenciaram e continuam influenciando, nas últimas quatro décadas, a elaboração de políticas curriculares nos planos nacional e internacional. Em

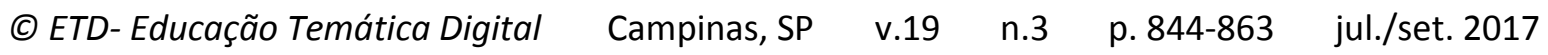


função dos objetivos e limites deste artigo, optamos por apresentar os argumentos de Young, sem obedecer a sequência cronológica de suas publicações.

Dos seus inúmeros trabalhos, dentre livros e artigos, analisamos mais detidamente "An approach to the study of Curricula as socially organized knowledge", capítulo primeiro do livro editado por ele em 1971, intitulado "Knowledge and control new directions for the sociology of education". Como ambos títulos - do referido capítulo e o da obra - anunciam que a dimensão sociológica fundamenta a significação da seleção do conhecimento escolar. Nos trabalhos mais recentes como "Knowledge and the Future School - curriculum and social justice", Young (2014) questiona tal fundamentação e faz duras críticas aos seus trabalhos anteriores especialmente ao "Knowledge and Control", livro considerado, por muitos, como pilar fundador da Nova Sociologia do Currículo, por apresentar, majoritariamente, teses e autores inseridos na tradição crítica do pensamento educacional, como Pierre Bourdieu (1971) que assina dois capítulos dessa obra intitulados "Intellectual Field and Creative Project" e "Systems of Education and Systems of Thought".

Para um melhor entendimento da construção dessa autocritica cumpre ampliar o campo de análise para além de suas obras acadêmicas e trazer para a análise elementos da sua participação direta nos bastidores da formulação de políticas públicas educacionais na Inglaterra e em outros países. É, por exemplo, a partir de sua narrativa autobiográfica, na qual ele relata a sua experiência com o movimento democrático na África do Sul, no início dos anos 90, que Young formula o conceito de "conhecimento poderoso". Como afirma este autor:

Foi por meio dessa leitura e de minha experiência na África do Sul que inverti os termos "poder" e "conhecimento": se o conceito original "conhecimento dos poderosos" se tornasse o novo conceito de conhecimento poderoso, poderíamos ter bases para fazer um conjunto de perguntas sobre o que seria um currículo que levasse a sério a ideia de direito para todos (YOUNG, 2016, p.33).

Nesse movimento destacamos algumas argumentações desenvolvidas por Young nas diferentes fases de seus escritos que incidem diretamente no sentido de seleção cultural mobilizada nos debates curriculares. A primeira faz referência ao reconhecimento da intrínseca articulação entre currículo e poder. Esse reconhecimento pode ser identificado na produção intelectual de Young dos anos 1970 quando opera com a categoria de análise "estratificação do conhecimento":

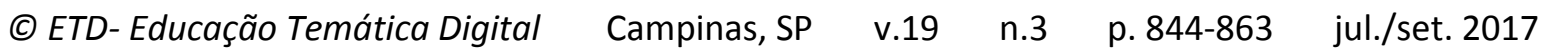


O poder de alguns para definir o que é conhecimento "valorizado" leva a problemas de contabilização de quão estratificado é o conhecimento e por quais critérios. Nessa ideia de "estratificação do conhecimento" está implícita a distinção entre "prestígio" e "propriedade", componentes de estratificação. [...] Isso sugere que, em diferentes sociedades, a concepção dominante do conhecimento pode ser semelhante à "propriedade privada", "propriedade" compartilhada por grupos específicos, ou comunitariamente regulada como na analogia da "terra comum" (YOUNG, 1971, p. 32 tradução livre).iii

O fragmento acima ilustra o protagonismo atribuído pelo autor às relações de poder ao operar com o conceito de "estratificação do conhecimento". A propósito dessa citação no texto de 1971, o autor lembrava reiteradamente o quanto os sociólogos haviam negligenciado a questão da seleção e organização do conhecimento (1971:19). Concordando com o trabalho de Raymond Williamsiv ${ }^{\text {, Young }}{ }^{\vee}$ naquela publicação, sublinhava que historicamente a seleção de conhecimento na escola pode ser percebida como ato de prestígio e de propriedade, o que denota o argumento em defesa da percepção de escola como objeto de investigação da sociologia do conhecimento $O$ autor reconhece, ainda, que a questão da "estratificação do conhecimento" não é exclusividade da sociologia da educação britânica, na segunda metade do século XX, e a considera como principal tema para uma reflexão social da escola.

Preocupado em explorar o potencial analítico do conceito de "estratificação do conhecimento", citando diferentes perspectivas teóricas e comparando estudos empíricos, a fim de identificar as estruturas sociológicas responsáveis pela diferenciação do conhecimento, Young reconhece nessa categoria de análise uma chave de leitura potente para o estabelecimento de critérios da ordem político-ideológica do que é considerado conhecimento curricular validado e legitimado para ser ensinado nas escolas da educação básica.

Em artigo de 1990, quando analisa a trajetória de Young, em especial sobre a publicação aqui citada, Moreira reforça a importância desse tipo de argumentação para pensar as contribuições da sociologia e seus efeitos nos debates educacionais que the eram contemporâneos. Para Moreira, o desafio posto naquela publicação era justificar o conhecimento escolar como objeto da Sociologia da Educação. Como afirma esse autor:

O foco central do artigo de Young, "An approach to the study of curricula as socially organized knowledge", é o conhecimento escolar, que passa a ser visto como socialmente construído. Segundo Young, educação é "uma seleção e organização do conhecimento disponível em um determinado momento, que envolve escolhas conscientes ou inconscientes" (1971, p. 24), o que significa dizer que um currículo não tem validade essencial e que reflete a distribuição de poder na sociedade mais ampla (MOREIRA, 1990, p.75)

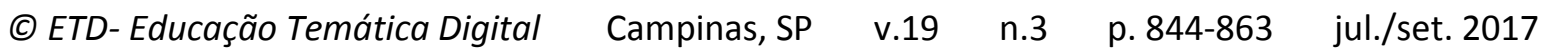


Ao procurar descrever a gênese da Nova Sociologia da Educação ou a emergência da Sociologia do Currículo, a partir principalmente da análise da produção teórica de Michael F. D. Young, Moreira defendeu que, apesar de reunir textos "diversos" e "contraditórios", a publicação de 1971 apresentou em comum a preocupação em responder às turbulências políticas da sociedade europeia, considerando que o projeto da Sociologia da Educação marcada pela plataforma teórica do funcionalismo estava profundamente desgastado (MOREIRA, 1990, p.31). Ao colocar em evidência a dimensão política da questão do conhecimento escolar, essa publicação repercutiu decisivamente para construção do currículo como problema investigativo. Para Moreira:

Era esta tentativa de definir o campo intelectual da Sociologia da Educação em torno do problema do conhecimento escolar, sua definição e transmissão, que unia o conjunto de artigos extremamente diversos e, em alguns casos, teoricamente contraditórios reunidos no livro KC vi (1990: p.31).

Sem dúvida, ainda que posteriormente esse autor (YOUNG, 2007) tenha inventariado o desserviço de abordagens nomeadas por ele como sócio-construtivistas, sua escrita de 1971 apresentou um caminho de diálogo potente com a tradição crítica no campo da sociologia, permitindo trazer à tona a complexa articulação entre os processos de produção curricular e as questões do poder e do controle do sentido. Vale destacar que a interface conhecimento-poder nunca foi descartada de sua reflexão, apesar de seus recentes escritos denunciarem que em 1971, ao priorizar as estruturas de estratificação do conhecimento, sua abordagem não teria se ocupado devidamente da questão da objetividade.

Seu movimento de autocritica, no nosso entendimento, não corresponde à uma negação ou substituição da abordagem político-ideológica, então predominante em seus estudos. Em outras palavras, percebemos na sua autocrítica um deslocamento ou descentramento mediante à incorporação do viés epistemológico que, segundo o próprio Young, teria sido silenciado ou pouco trabalhado em seus escritos dos anos de 1970. Não é por acaso que suas recentes análises $(2008 ; 2012$; 2014, 2016) seguem operando com a oposição "conhecimento dos poderosos" e "conhecimento poderoso" (2007), ou ainda "currículo por engajamento" e "currículo por acatamento" (2011), com o intuito de sublinhar o protagonismo do conhecimento escolar para promoção da justiça social. Retomaremos a essas categorias ao longo de nossa argumentação.

Por ora, cabe sublinhar o fato de essa autocrítica remeter à segunda ordem de argumentação presente nas produções mais recentes de Young $(2008,2014,2016)$ que nos interessa trazer para a reflexão. Referimo-nos à ideia de diferenciação do conhecimento, estreitamente associada às "estruturas de especialização". Segundo Young, o conhecimento curricular ou disciplinar se diferencia do conhecimento cotidiano,

$\begin{array}{llllll}\text { C C ETD-Educação Temática Digital } & \text { Campinas, SP } & \text { v.19 } & \text { n.3 } & \text { p.844-863 } & \text { jul./set. } 2017\end{array}$ 
baseado na experiência $(2008,2014)$, sendo o primeiro articulado à ideia de "conhecimento poderoso", cuja potência para pensar a democratização da escola não deve, segundo este autor, ser negligenciada

Para revisão de seus trabalhos, Young propôs, por exemplo, o diálogo mais forte com as obras de Émile Durkheim e Basil Bernstein vii, a fim de fortalecer a significação da seleção do conhecimento, mais no terreno do epistemológico e menos no do ideológico. Em resumo, nos artigos publicados nos anos 2000, Young concordou com seus críticos viii, afirmando que o argumento sócio-construtivista não é capaz de dar conta da validade do conhecimento. Nesses textos, ele analisa no que (e se de fato) fracassou a nova sociologia da educação. Young com Müller avaliaram que: "(...)a "nova” sociologia da educação, que teve início com um compromisso radical com a veracidade, usando os termos de Williams, enfraqueceu seu próprio projeto, rejeitando qualquer ideia da verdade propriamente dita". (YOUNG \& MULLER, 2007, p. 164). No cerne daquela afirmativa estaria a ideia de que o projeto da Sociologia do Currículo se furtou de crer na objetividade do conhecimento a fim de fortalecer a determinação econômica e sociológica na discussão do conhecimento como construção social.

A questão da interface objetividade-verdade do conhecimento torna-se assim, objeto caro de sua reflexão, principalmente quando se propõe a revisitar seus trabalhos. Ela está presente, por exemplo, na sua discussão de "conhecimento poderoso" (2007; 2010) ou "currículo por engajamento" (2010), em que reconhece que a objetividade é construída socialmente e tributária de um corpo institucional que regula a diferenciação do conhecimento, segundo ele, sem a interferência dos princípios ideológicos. Young, nas expressões citadas, projetou sua releitura sobre a relação entre conhecimento e educação, rejeitando à definição redutora de currículo como sistema reprodutor das desigualdades sociais.

Essa abordagem do conhecimento escolar com foco em sua objetividade, em distintos artigos $(2011,2014,2014 a)$, vem recuperando o debate sobre a disciplinarização, ou o conhecimento especializado que, segundo ele, teria potencial para ser institucionalmente validado. Afinal,

O conhecimento no currículo é basicamente um conhecimento especializado, em geral (mas nem sempre) organizado para ser transmitido de uma geração para outra. Uso o verbo "transmitir" sem presumir que seja um processo de mão única, como pode insinuar a metáfora. O conhecimento no currículo é o fenômeno sobre o qual os teóricos do currículo dizem ter conhecimento especializado, e é essa teoria do currículo que deveria nos permitir analisar e criticar suas diferentes formas e, esperemos, desenvolver e propor alternativas melhores de currículo. (YOUNG, 2014a, p. 200).

(C) ETD-Educação Temática Digital Campinas, SP $\quad$ v.19 $\quad$ n.3 $\quad$ p.844-863 jul./set. 2017 
A argumentação acima descrita é desenvolvida também no já mencionado artigo "Why educators must differentiate knowledge from experience?" (2008) cujo título, uma interrogação, sinaliza o imperativo da diferenciação (ou da natureza diferencial do conhecimento), que pode ser percebido como uma provocação com o intuito de convencer os docentes da centralidade do conhecimento, isto é para tomá-lo como imperativo da escola, se posicionando, assim, contrariamente às perspectivas pedagógicas relativistas pautadas na experiência.

Do mesmo modo, o engajamento proposto por Young (op.cit.) centra-se mais no conhecimento especializado das disciplinas do que no saber prévio ou cotidiano do aluno Dito de outra forma, em diferentes textos, Young construiu uma argumentação que revê seus estudos dos anos 1970 para justificar a relevância do currículo centrado no conhecimento disciplinarizado como ilustra o fragmento abaixo:

\footnotetext{
O título deste artigo salienta a importância de distinguir o conhecimento da experiência. Meu primeiro livro KC, foi de opinião contrária. Eu inverti as prioridades convencionais nesse tempo e privilegiei a experiência sobre o conhecimento. Argumentei que a distinção entre conhecimento e experiência era ideológica e baseada no poder daqueles que definem o que conta como conhecimento, em vez de quaisquer critérios objetivos. (2010:11, tradução livre) $)^{\mathrm{ix}}$
}

Embora não seja o objetivo central deste texto, cumpre observar que a ideia de especialização do conhecimento (tal como trabalhada por Young) produz efeitos paradoxais sobre a forma de significar o trabalho docente, gerando debates acirrados no campo educacional. De um lado, essa abordagem permite operar com a ideia de empoderamento do trabalho docente, na medida em que abre espaço para recuperar a imagem desse profissional associada à um personagem intelectual no processo de ensino e aprendizagem. Afinal, os professores são responsáveis por mobilizar e socializar esse conhecimento especializado, poderoso.

De outro lado, porém, essa mesma ideia de especialização do conhecimento, ao ser mobilizada igualmente na diferenciação entre "pedagogia" e "currículo", tende a produzir efeitos opostos às anteriormente assinaladas na reflexão sobre trabalho docente. Para Young, enquanto a primeira se ocuparia dos procedimentos de ensino para aquisição do conhecimento- envolvendo necessariamente o trabalho docente - o segundo, focaliza a seleção e deve ser de exclusiva preocupação de especialistas, retirando, nesse caso, o protagonismo docente (2010). Ainda que, em texto recente, Young tenha reconsiderado o papel do docente no desenho curricular e definido a pedagogia como "relação de autoridade" no processo de ensino-aprendizagem (2014a, p. 196), nos parece que essa perspectiva atual de currículo em Young, apoiada nas estruturas de especialização (ao operar com a distinção entre pedagogia e currículo, por
(C) ETD-Educação Temática Digital
Campinas, $\mathrm{SP}$
v.19
n.3
p. $844-863$
jul./set. 2017 
exemplo), corre o risco de reatualizar discursos desfavoráveis à agenda política em torno do trabalho docente.

A defesa da centralidade do conhecimento objetivo e poderoso nos debates curriculares está diretamente associada a uma terceira ordem de argumentação que gostaríamos de sublinhar na medida em que entendemos como sendo aquela que permeia toda a sua trajetória, conferindo continuidade entre seus escritos e coesão em seus estudos curriculares: a estreita associação entre currículo, conhecimento e educação. Uma breve revisão da trajetória desse o autor permite perceber que suas reconsiderações sobre a concepção de currículo necessariamente dependem de suas sequentes releituras sobre a relação entre o conhecimento e a educação.

Por essa razão, reiteradamente, sugere a importância dos estudos sociológicos de Basil Bernstein e Émile Durkheim para reabilitar a função da escola cuja institucionalidade depende justamente da diferenciação do conhecimento diante de outros saberes. Interpretamos que o projeto de diferenciação do conhecimento é um entendimento da seleção curricular em contexto escolar. O que, para Young, implicaria na definição do currículo por engajamento ou na seleção das "escolhas curriculares [que] têm de ser tratadas pelo que são: maneiras alternativas de promover o desenvolvimento intelectual dos jovens" (YOUNG: 2010, p.22).

Em resumo, no exercício de rever seus estudos anteriores, ele reconhece a importância da função da escola em construir o sujeito intelectual e por esta razão questiona seguramente a relação da aprendizagem com o currículo, o que o leva a reposicionar a relação entre o sujeito aluno e a seleção do conhecimento.

No conjunto desses argumentos, é possível perceber que a crítica aos trabalhos de 1971 reside na revisão do entendimento de seleção do conhecimento. Se nos escritos originais, a denúncia das imbricações do conhecimento escolar com as relações de poder tende a priorizar a experiência do aluno como critério e/ou espaço de decisão para a seleção do conhecimento, nos estudos recentes, Young inverte seu argumento e privilegia as entidades, como as comunidades disciplinares, que asseguram a objetividade do conhecimento como responsáveis pela seleção, isto é, pela validade do que seja ensinado nas escolas.

Como mencionado na introdução, nosso distanciamento em relação às proposições de Young se situa menos nas atuais questões formuladas sobre o processo de seleção do conhecimento escolar do que na escolha do quadro teórico no qual as repostas foram pensadas.

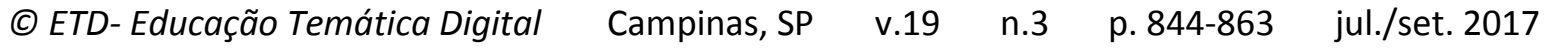


Com efeito, as formulações mais recentes aqui brevemente apresentadas se inscrevem no deslocamento teórico realizado por Young no âmbito da sociologia do conhecimento de uma perspectiva "sócio-construtivista" para o que ele nomeia de "realismo social". Para Young essa última se apresenta como perspectiva oportuna para pensar criticamente a escola numa linha mais propositiva na medida em que abre pistas para pensar a objetivação do conhecimento. Como aponta Young (2008)

\begin{abstract}
Como tem sido argumentado em outra parte deste livro, uma sociologia muito diferente do conhecimento decorre do pressuposto de que o conhecimento é diferenciado; me referi a ela como o realismo social. Ao contrário do construtivismo social, que trata só a base social do conhecimento como real e objetiva, o realismo social trata tanto a base social do conhecimento como o próprio conhecimento como real. Segue-se que, em vez de se concentrar apenas na crítica ideológica, uma abordagem realista e social para o currículo procura identificar as condições sociais que possam ser necessárias se o desejo é adquirir conhecimento objetivo. É uma abordagem do conhecimento que tem sido muito negligenciada até recentemente na sociologia da educação, e por educadores de forma geral. (YOUNG, 2008:165, tradução livre) ${ }^{x}$.
\end{abstract}

Entendemos que a defesa do conhecimento objetivo, no quadro do realismo social proposto por Young, reatualiza dicotomias fundamentadas em essencialismos metafísicos, já exaustivamente combatidos pelas teorizações sociais contemporâneas. Argumentaremos, pois, na próxima seção que - ao contrário do que tem sido afirmado por Young e seus seguidores - as perspectivas pós-estruturalistas no campo curricular, além de não negarem necessariamente a importância do conhecimento escolar, oferecem subsídios teóricos para a reflexão sobre objetivação do conhecimento que merecem ser explorados pelos pesquisadores do campo.

Nessa direção, caberia argumentar a respeito do potencial da discussão de Young que favoreceu a reflexão sobre conhecimento na escola, o que para nós pode ser percebido como questão passível de ser revisitada e compreendida à luz do debate sobre o antagonismo, uma vez que, em linhas gerais, se trata da seleção como a fundação [precária, porém duradoura] da validade do conhecimento.

\title{
A SELEÇÃO COMO ANTAGONISMO: UMA QUESTÃO CURRICULAR
}

O desafio que nos propomos nesta seção consiste em simultaneamente concordar com a aposta de Young relacionada à importância atribuída à objetivação do conhecimento escolar no entendimento do significado de seleção curricular e problematizar a argumentação teórica mobilizada por esse autor para sustentá-la.

Os argumentos desenvolvidos por esse autor contra o que ele nomeia de perspectivas "anticonhecimento" (YOUNG, 2016, p.29), embora operem com a ideia de
(C) ETD-Educação Temática Digital
Campinas, $\mathrm{SP}$
v.19
n.3
p. $844-863$
jul./set. 2017 
que o conhecimento é uma construção social, tendem, em nosso entendimento, a naturalizar e reforçar pares dicotômicos entre termos como "ciência" e "cultura" ou "conhecimento" e "experiência", na medida em que não problematizam - de forma consistente do ponto de vista teórico - os sentidos hegemonizados nos campos político e educacional de cada um desses significantes.

Essa observação é importante, porque nos permite colocar em evidência alguns aspectos da argumentação desse autor dos quais nos afastamos. Referimo-nos em particular ao enfrentamento dos efeitos das perspectivas essencialistas nas análises do social.

Para Young, a defesa da inclusão da dimensão objetiva na definição dos critérios de seleção do conhecimento escolar passa necessariamente pela valorização da organização disciplinar e das comunidades disciplinares, vista por esse autor como sendo a instância responsável por responder às "regras acordadas entre os professores especialistas dessas disciplinas sobre o que é considerado conhecimento válido" (YOUNG, 2016, p.27). Percebe-se que nesse tipo de afirmação a validação do conhecimento não é justificado de forma descontextualizada ou a-histórica, mas sim como resultado de negociação entre sujeitos posicionados em lugares de enunciação específicos. No entanto, o que é negociado, ou mais precisamente os sentidos de termos como os de objetividade, verdade, ciência, nesse contexto, permanece sem maiores problematizações. O mesmo movimento que contextualiza e reconhece a singularidade do espaço no qual o conhecimento escolar validado é definido a partir de critérios pactuados no âmbito de um determinado grupo apaga as bases epistemológicas sobre as quais esses critérios são estabelecidos para esse tipo de validação.

Considerando os debates epistemológicos contemporâneos, a problematização desse apagamento nos parece não apenas pertinente, mas igualmente necessário. Interrogar-nos sobre os sentidos fixados de ciência, cultura, conhecimento ou experiência com os quais operamos em nossas pesquisas não é apenas uma questão retórica, mas também e sobretudo uma questão política.

Para sustentar essa afirmação, trazemos para o debate as contribuições das teorizações pós-estruturalistas, em particular as formuladas no âmbito da abordagem discursiva pós-fundacional (LACLAU, MOUFFE. 2005; MARCHAT, 2009), em particular no que elas incidem na leitura política do social. Interessa-nos, como indica o título atribuído a essa seção, argumentar a favor da categoria "antagonismo" como chave de leitura para pensarmos a questão da seleção/objetivação do conhecimento validado para ser ensinado nas escolas.

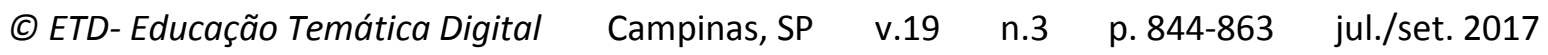


O pensamento pós-fundacional, no qual se inscreve a teoria do discurso de Ernesto Laclau e Chantal Mouffe (2005) se sustenta teoricamente na radicalização da crítica ao essencialismo por meio do questionamento da ideia de fundamento metafísico e do papel que lhe é atribuído nos processos de significação. Dito de outra maneira, ele se distancia das perspectivas que consideram que o ser das coisas desse mundo - sonhos e pedras - se define por uma essência situada fora dos jogos da linguagem. $\mathrm{Na}$ abordagem aqui privilegiada, não é possível definir algo per si. Isso implica em considerar que $o$ ato de significar é sempre relacional e ocorre em meio às múltiplas possibilidades de definição disponíveis em um contexto discursivo específico.

Desse modo, o discurso, percebido como categoria teórica - e não descritiva ou empírica - permite apreender as regras de produção de sentido pelas quais um determinado fenômeno encontra seu lugar no mundo social e numa determinada formação discursiva. A teoria do discurso, na pauta pós-fundacional se propõe portanto, analisar:

[...] o modo pelo qual forças políticas e atores sociais constroem significados dentro de estruturas sociais incompletas e indecidíveis. Isto é alcançado por meio do exame de estruturas particulares dentro das quais os agentes sociais tomam decisões e articulam projetos hegemônicos e formações discursivas. Além disso, teóricos do discurso procuram localizar essas práticas e lógicas investigadas em contextos históricos e sociais mais amplos, de maneira que eles possam adquirir uma significação diferente e fornecer a base para uma possível crítica e transformação de práticas e significados sociais existentes. (HOWARTH, 2000, p. 3, tradução livre).

Nesse quadro de inteligibilidade, o processo de estruturação de uma ordem social qualquer (como o currículo escolar, por exemplo) consiste em uma operação discursiva em meio a um sistema relacional e diferencial: "algo é o que é somente por meio de suas relações diferenciais com algo diferente" (LACLAU, 2005, p.92). Nesse processo, entram em jogo simultaneamente as lógicas de equivalência e da diferença. A primeira é responsável pelo enfraquecimento da diferença entre elementos, sem, no entanto, eliminá-la por completo, pois nesse caso a dimensão relacional seria negada e a significação/ definição da estrutura estaria pautada em uma essência, isto é, por algum fundamento situado 'fora' do jogo da linguagem. A segunda lógica, por sua vez, atua de forma a produzir uma ruptura, um corte radical que interrompe a cadeia de equivalência produzida pela primeira lógica, emergindo assim, como condição de possibilidade de toda significação. Afinal, como afirma Laclau (1996)

(C) ETD-Educação Temática Digital $\quad$ Campinas, SP $\quad$ v.19 $\quad$ n.3 $\quad$ p.844-863 $\quad$ jul./set. 2017 
De tal modo nos encontramos na situação paradoxal de que aquilo que constitui a condição de possibilidade de um sistema significativo, seus limites, é também aquilo que constitui sua condição de impossibilidade, um bloqueio na expansão contínua do processo de significação (LACLAU, 1996, p.71, tradução livre)

Nessa perspectiva dois conceitos, redimensionados na pauta pós-fundacional hegemonia e antagonismo - tornam-se importantes ferramentas de análise, oferecendo a possibilidade de uma outra leitura política do social e, em particular, no que nos interessa neste texto, uma releitura da seleção cultural.

Entendido como uma prática articulatória discursiva definidora do próprio jogo político, o conceito de hegemonia seria assim, a mola propulsora da ação política, conforme afirmam Laclau e Mouffe (2005). Segundo esses autores, todo discurso hegemônico é um particular que se hegemoniza e se torna universal, por meio de uma ação contingente, precária e construída diante das negociações possíveis. Nesse movimento, uma particularidade assume a função universal, caracterizando, assim, o que Laclau e Mouffe (2005) chamam de uma relação hegemônica.

É a necessidade de fechamento e de sutura investida nesse mesmo movimento de hegemonização/homogeneização que provoca o antagonismo, reafirmando a impossibilidade de qualquer fechamento definitivo. Afinal, os antagonismos

(...) revelam a contingência e precariedade de toda identidade e objetividade social, uma vez que qualquer identidade é sempre ameaçada por algo que lhe é externo. (...) A partir dessa ótica, antagonismos revelam os limites ou fronteiras políticas de uma formação social, porque eles mostram os pontos onde a identidade não pode mais ser estabilizada em um sistema de diferenças significativo, sendo contestada por forças que se situam no limite daquela ordem. (HOWARTH, 2000, p.5)

Assim, nas disputas travadas em meio ao jogo da linguagem, todo discurso busca produzir uma fronteira entre elementos que estão "dentro" e aqueles que estão "fora" de uma determinada formação discursiva. Tudo aquilo que está fora da cadeia de equivalência de um determinado discurso torna-se um excesso que, na infinitude do social, é significado como o "outro" antagônico a cada um dos elementos articulados naquele discurso. Isso permite afirmar que se o antagonismo é necessário para a construção ou para a estabilização transitória de todo significado, então todo sentido de qualquer categoria é radicalmente político. (MARCHART, 2009).

Hegemonizar significa fixar e universalizar provisoriamente um sentido particular mediante a produção de pontos nodais e simultaneamente produzir seu outro antagônico, o expelindo da cadeia hegemônica. Significa produzir dispositivos de esquecimento do momento instituinte da contingência de toda ordem social. Do mesmo
(C) ETD-Educação Temática Digital
Campinas, SP
v.19
n.3
p. $844-863$
jul./set. 2017 
modo, como totalidade fissurada, a sociedade/ordem social é um terreno no qual é sempre possível o momento da lembrança da contingência, oferecendo possibilidades conceituais para pensar a abertura do social. A luta política consiste, portanto, em lutas pela significação, isto é, pela sedimentação e reativação de sentidos de social.

Ao negar a possibilidade de um sentido unívoco e previamente estabelecido, essa postura epistêmica não só coloca em evidência o papel da contingência, como a radicaliza, nos processos de significação. Isso pressupõe reconhecer que nenhum ato de significação é possível fora de um sistema de diferenças. Quando operamos com termos como, por exemplo, "objetividade", "ciência", "verdade", ou ainda "seleção curricular", "conhecimento especializado" ou "conhecimento objetivo", estamos participando das disputas pela significação em meio ao jogo de linguagem praticado em meio à diferença.

Nessa perspectiva, o que está em jogo é menos a fronteira da estrutura de diferenciação do conhecimento do que o lugar da fronteira que opera o corte do que é ou não é conhecimento escolar. Questionamos assim a estabilidade ou fixidez da fronteira de diferenciação do conhecimento pretendida na argumentação deste autor. $O$ que nos leva a questionar, principalmente, suas metáforas binárias e sua concepção do conhecimento especializado (YOUNG, 2014) com a qual ele introduz e sustenta a questão da objetividade.

A aposta no entendimento de seleção como operação antagônica se inscreve nesse tipo de questionamento. Pelo que apresentamos anteriormente, é possível estabelecer uma articulação entre os termos seleção, antagonismo e objetividade do conhecimento. A decisão de selecionar, nessa perspectiva, corresponde à produção do corte radical definidor do que é e do que não é validado como conhecimento escolar. É, pois, um processo decisório contingencial que incide diretamente na escolha do lugar do corte radical, isto é do lugar da fronteira. Assim, a seleção curricular se inscreve na aporia que representa a tensão entre a necessidade e impossibilidade de qualquer processo de significação. $O$ ato de selecionar não corresponde à escolha - em meio a um conjunto de saberes previamente estabelecidos - de conhecimentos que serão validados, e sim ao próprio ato politico de decisão curricular.

À luz da teoria laclauniana, seria viável dizer então, que a seleção curricular é a operação antagônica de um sistema que estabiliza os sentidos hegemônicos, ou seja, os que foram garantidos contingencialmente como objetos de ensino. Essa operação antagônica promove a fronteira política que identifica aquele conhecimento passível de ser ensinado e tem, por exemplo, no item de uma prova institucional, um potente texto curricular de repercussão em escala nacional.

$\begin{array}{llllll}\text { (C) ETD-Educação Temática Digital } & \text { Campinas, SP } & \text { v.19 } & \text { n.3 } & \text { p. 844-863 } & \text { jul./set. } 2017\end{array}$ 
O antagonismo é o momento da contenção do sistema de significação. O que vem a ser a interdição do fluxo de sentidos. A contenção do sistema é produtora de qualquer identidade. Diante dessa inspiração laclauniana, é válido reiterar que a seleção do conhecimento pode ser interpretada como momento diferencial que contém precariamente os sentidos, fixando a distinção entre o que é, ou que deixa de ser, passível de ser ensinado.

Para Laclau, o antagonismo impede a plenitude da ordem, da essência, por encarnar seu próprio limite. Como ele mesmo propôs, o antagonismo é o exterior constitutivo (da significação), que bloqueia a identidade do interior. A definição de antagonismo (LACLAU, 2000) é central para a nossa ambição de reler a seleção sob a interpretação do discurso, perseguindo uma análise que recusa a definição de conhecimento como fundamento último, isto é, como reificado, e que ao mesmo tempo reposiciona o debate sobre o limite da objetividade. Ao invés de pensarmos no conhecimento objetivado como algo que precede e determina o processo de seleção, propomos significar a seleção como a própria possibilidade de objetividade.

Nessa abordagem, o conhecimento especializado ou poderoso tem o compromisso de estar no domínio do verdadeiro e pode ser significado como um elemento, entre outros, da cadeia definidora do escolar. Isso significa que o conhecimento escolar passa a ser visto como uma configuração discursiva resultante da articulação de diferentes unidades, entre elas, o conhecimento discisplinarizado ou especializado que trabalha e respeita os regimes de verdade legitimados tanto pelas comunidades acadêmicas disciplinares quanto pelos especialistas em educação.

Nossa argumentação da seleção curricular é convergente com o horizonte do debate democrático. Para tanto, consideramos que é impossível incluir todas as combinatórias das certezas num texto curricular. Ademais, nos compete sobretudo pensar a função discursiva reveladora do antagonismo ao impor os limites temporais e espaciais da "certeza", inaugurando uma provisória validade do conhecimento.

A teoria do discurso de Ernesto Laclau nos autoriza a pensar que as clivagens desenhadas por Young (2008, 2014 a), citadas anteriormente, tenderiam a apagar os processos que estruturam a decisão curricular. Isto porque a objetividade concebida como sistema centrado e encerrado permitiria uma versão da seleção do conhecimento objetivado que esvazia a interpretação da ideia de disputa em torno da decisão curricular. Em poucas palavras, a inspiração da teoria do discurso faculta uma interpretação da objetividade como território da seleção conhecimento. Ou seja, a objetividade é decidida na luta para dizer o que venha a ser conhecimento no currículo.

$$
\text { (C) ETD-Educação Temática Digital } \quad \text { Campinas, SP } \quad \text { v.19 } \quad \text { n.3 } \quad \text { p.844-863 jul./set. } 2017
$$




\section{CONSIDERAÇÕES FINAIS}

O desenho conceitual - seleção do conhecimento escolar e antagonismo - é aqui teoricamente arquitetado para questionar a fixação hegemonizada do sentido de objetividade, incorporada nos escritos recentes de Young. Cabe repetir que esse desenho conceitual responde à pauta educacional, centrada na compreensão da complexa relação entre poder e conhecimento.

Investigar nesses parâmetros os processos de seleção do conhecimento é, como temos defendido em outros espaços (GABRIEL, 2016; ROCHA e GABRIEL, 2014), problematizar as lógicas de garantias em torno de determinados saberes, considerados e estabilizados como os verdadeiros, os mais legítimos e, por isso, mais válidos do que outros, objetos de uma precária exclusão.

Com efeito, o exercício teórico aqui ensaiado resulta da recusa radical da compreensão da seleção, em uma perspectiva que apresente vestígios essencializantes e pela qual o entendimento de conhecimento objetivado e verdadeiro mobiliza a ideia de fundamento último.

Assim, sustentamos ao longo deste texto que compreender a objetividade do conhecimento escolar a partir do pós-fundacionismo implica colocá-la em um outro plano conceitual. Ou seja, deslocar o foco da busca de uma preocupação de definição de "conhecimento objetivo" para uma redefinição, ressignificação da ideia de objetividade em um paradigma radicalmente antiessencialista. Esse deslocamento - ao permitir compreender que "o discurso constitui o terreno primário da objetividade como tal" ( LACLAU, 2005, p.92) , que o lugar da objetividade é resultante da luta hegemônica e que selecionar remete, por sua vez, a ações de objetivação resultantes de operações antagônicas - deixa entrever pistas de investigação a serem trilhadas pelos interessados em continuar insistindo e persistindo na importância da questão do conhecimento escolar para a construção da agenda contemporânea da política educacional e, em particular, curricular.

\section{REFERÊNCIAS}

GABRIEL, Carmen Teresa. Conhecimento escolar e emancipação: uma leitura pós-fundacional. Cadernos de Pesquisa (Fundação Carlos Chagas. Impresso): 2016. p. 104-130, (v. 46). Disponível em: http://www.scielo.br/scielo.php?pid=S0100$15742016000100104 \&$ script=sci abstract\&tIng=pt Acesso em agosto de 2016.

HOWARTH, David. Discourse. Open University Press. Buckinghtam, Philadephia: 2000.

(C) ETD-Educação Temática Digital $\quad$ Campinas, SP $\quad$ v.19 $\quad$ n.3 $\quad$ p.844-863 jul./set. 2017


LACLAU, Ernesto. Razón Populista. Buenos Aires: Fondo de cultura económica, 2009.

LACLAU, Ernesto. E MOUFFE, Chantal. Hegemonia y estrategia socialista - hacia uma radicalización de La democarcia. Buenos Aires: Fondo de cultura económica, 2005.

LACLAU, Ernesto. Nuevas reflexiones sobre la revolución de nuestro tiempo. Buenos Aires: Nueva Visión, 2005.

LACLAU, Ernesto. Misticismo, retorica y política. Buenos Aires: Fondo de Cultura Economica, 2000.

MARCHART, Olivier. El pensamento político pós-fundacional, La diferencia política en Nancy, Lefort, Badiou Y Laclau. Buenos Aires: Fondo de Cultura Economica, 2009.

MOREIRA, Antônio Flávio Barbosa. Sociologia do Currículo: origens, desenvolvimento e contribuições. IN: Em Aberto. Brasília, DF: 1990. pp. 72-83. (ano 9. n. 46. Abr./ jun.).

ROCHA, Ana Angelita E GABRIEL, Carmen Teresa. ENEM nos documentos: uma leitura pósfundacional da reestruturação do exame em 2009. Revista e-Curriculum (PUCSP), p. 19932018. 2014. (v. 12). Disponível em: http://www.redalyc.org/pdf/766/76632904013.pdf Acesso em agosto de 2016.

YOUNG, Michael. Por que o conhecimento é importante para as escolas do século XXI? Cadernos de Pesquisa, mar. 2016. p. 18 - 37, (vol. 46, n. 159). Disponível em: http://www.scielo.br/pdf/cp/v46n159/1980-5314-cp-46-159-00018.pdf. Acesso em agosto de 2016.

YOUNG, Michael. Teoria do currículo: o que é e por que é importante? Cadernos de Pesquisa. Jan.-mar. 2014. p. 190 - 202. (vol. 44, n. 151). Disponível em: http://www.scielo.br/pdf/cp/v44n151/10.pdf. Acesso em julho de 2016.

YOUNG, Michael; LAMBERT, David. Knowledge and the future sochool - curriculum and social justice. Bloomsbury Academic Publishing, Londres: 2014.

YOUNG, Michael. O futuro da educação em uma sociedade do conhecimento: o argumento radical em defesa de um currículo centrado em disciplina. Revista Brasileira de Educação: dez/2011. p.609-623. (vol. 16, n.48).

YOUNG, Michael. Para que servem as escolas? IN: Educação \& Sociedade, Campinas, SP, set./dez. 2007. p. 1287-1302. (vol. 28, n. 101). Disponível em <http://www.cedes.unicamp.br>. Acesso em janeiro, 2010

YOUNG, Michael. Bring Knowledge Back In - From social constructivism to social realism in the sociology of education. Routledge, London and New York: 2008. 
YOUNG, Michael. \& MÜLLER, Johan. Verdade e Veracidade na sociologia do conhecimento educacional. IN: Educação em Revista/UFMG, Belo Horizonte, MG, jun. 2007. p. 159-196, (v.45).

YOUNG, Michael; GAMBLE, Jeanne (Ed.) Knowledge, curriculum and qualifications for South African Futher Education. HSRC PRESS, Cape Town (S. A), 2006.

\title{
YOUNG, Michael. O currículo do futuro - Da nova sociologia da educação a uma teoria crítica do aprendizado. Campinas, SP: Papirus, 2000.
}

YOUNG, Michael. (Org.) Knowledge and Control: New Directions in the Sociology of

Education. Collier-Macmillan, Londres: 1971.

\begin{abstract}
i De acordo com o portal eletrônico, o Movimento se define como "um grupo diverso - composto por pessoas com longo histórico de atuação em instituições relevantes no cenário educacional brasileiro decidiu se mobilizar pela causa da construção da Base Nacional Comum e vem buscando colocar em prática as ações que possam facilitar e acelerar esse processo." Disponível em: http://basenacionalcomum.org.br/o-movimento/Acesso em: setembro de 2015.
\end{abstract}

ii Em uma de suas passagens pelo Brasil, em 2013, Young participou como conferencista no Seminário "Construindo uma base nacional comum", evento idealizado e organizado pelo Conselho Nacional de Secretários de Educação e pela Fundação Lemann. Vale mencionar que nesta ocasião foram desenhadas certas proposições para a base nacional curricular, em que participaram fundadores e integrantes desse movimento

iiiThe power of some to define what is "valued" knowledge leads to problems of accounting for how "stratified" knowledge is and by what criteria. Implicit in this idea of "stratification of knowledge" is the distinction between the "prestige" and the "property" components of stratification. [...] It suggests that in different societies the dominant conception of knowledge may be akin to "private property", "property" shared by particular groups, or communally available on the analogy of "common land". (YOUNG, 1971: p. 32)

iv Ao longo do artigo citado, Young destacou a influente obra de Williams, publicada em 1961, intitulada "The long revolution". Sobre a leitura de Young daquele autor, é válido reproduzir o seguinte trecho: With a neo- Marxist framework, Williams (1961) provides perhaps the most promising and (by sociologists) most neglected approach to the study of content of education. (...) He then sugests that curricula changes have reflected the relative power of the differente groups over the last hundred years (Idem: 29).

` Para tal afirmação, nossas análises se voltam também para o artigo An approach to the study of curricula as socially organized knowledge (1971: 19-46).

${ }^{v i}$ Referente à obra Knowledge and control - new directions for the sociology of education (YOUNG, M.F.D., 1971).

(C) ETD-Educação Temática Digital Campinas, SP $\quad$ v.19 $\quad$ n.3 $\quad$ p. 844-863 jul./set. 2017 
vii A perspectiva sociológica para conceber o conhecimento escolar, desenvolvida pelo sociólogo inglês Basil Bernstein (1971; 2000), influencia decisivamente os trabalhos de Young (1971, 2000, 2007). Em linhas gerais, sua abordagem enfatiza o papel das fronteiras do conhecimento, como uma condição para a sua aquisição e é substantivamente atrelada às relações de poder que estão necessariamente envolvidas na pedagogia. Neste argumento, a concepção de enquadramento pode ser forte - quando há profunda clivagem do /no conhecimento escolar e o não-escolar - ou fraco, quando as fronteiras entre o conhecimento escolar e não-escolar são diluídas. Aliás, Young associa este "enquadramento fraco" à "programa de educação adulta e alguns currículos planejados para alunos menos capazes" (YOUNG: 2008)

viii No que diz respeito aos críticos do trabalho de 1971 de Young e mesmo à revisão do próprio nos recentes trabalhos, convém citar Moreira (1990), além dos artigos (Young \& Muller, 2007, Young, 2010, 2008).

ix The title of this paper stresses the importance of distinguishing knowledge from experience. My first book $\mathrm{KC}$, took the opposite view. I inverted the conventional priorities of the time and privileged pupil experience over knowledge. I argued that the distinction between knowledge and experience was ideological and relied on the power of those defining what counted as knowledge rather than any objective criteria. (2010:11).

${ }^{x}$ As has been argued elsewhere in this book, a very different sociology of knowledge follows from the assumption that knowledge is differentiated; I have referred to it as social realism. Unlike social construcionism, which treats only the social basis of knowledge as real and objective, social realism treats both the social basis of knowledge and itself as a real. It follows that instead of concentrating solely on ideology critique, a social realist approach to the curriculum seeks to identify the social conditions that might be necessary if objective knowledge is to be acquired. It is an approach to knowledge that has been much neglected until recently in the sociology of education, and by educationalists generally. (YOUNG, 2008:165). 